\title{
Detection of human epidermal growth factor receptor 2 overexpression in canine anal sac gland carcinoma
}

\author{
Sho YOSHIMOTO ${ }^{1)}$, Daiki KATO ${ }^{1) *}$, Satoshi KAMOTO ${ }^{1)}$, Kie YAMAMOTO2), \\ Masaya TSUBOI $^{3)}$, Masahiro SHINADA ${ }^{1}$, Namiko IKEDA ${ }^{1)}$, Yuiko TANAKA ${ }^{1)}$, \\ Ryohei YOSHITAKE ${ }^{1)}$, Shotaro ETO ${ }^{1)}$, Kohei SAEKI ${ }^{1)}$, James Kenn CHAMBERS ${ }^{3)}$, \\ Ryohei KINOSHITA ${ }^{2)}$, Kazuyuki UCHIDA ${ }^{3)}$, Ryohei NISHIMURA ${ }^{1)}$ and \\ Takayuki NAKAGAWA ${ }^{1)}$
1)Laboratory of Veterinary Surgery, Graduate School of Agricultural and Life Sciences, The University of Tokyo, 1-1-1, Yayoi, Bunkyo-ku, Tokyo 113-8657, Japan
2) Veterinary Medical Center, The University of Tokyo, 1-1-1 Yayoi, Bunkyo-ku, Tokyo 113-8657, Japan
3) Laboratory of Veterinary Pathology, Graduate School of Agricultural and Life Sciences, The University of Tokyo, 1-1-1 Yayoi, Bunkyo-ku, Tokyo 113-8657, Japan

J. Vet. Med. Sci.

81(7): 1034-1039, 2019

doi: 10.1292/jvms.19-0019

Received: 12 January 2019

Accepted: 17 May 2019

Advanced Epub:

29 May 2019
ABSTRACT. Canine anal sac gland carcinoma (ASGC) frequently occurs in the apocrine glands of the canine anal sac and shows aggressive biological behavior. The expression of human epidermal growth factor receptor 2 (HER2) has been reported in various human and canine tumors. HER2 is a promising therapeutic target of these tumors, and HER2-targeted drugs, such as trastuzumab and lapatinib, have improved the outcome of these patients. In this study, HER2 expression in ASGC was evaluated to investigate its potential as a therapeutic target for canine ASGC. HER2 mRNA expression in surgically resected ASGC tissues was significantly higher than that in normal anal sac tissue. To evaluate the expression of HER2 protein, paraffin-embedded ASGC tissues were immunohistochemically evaluated. Strong and broad staining of HER2 was detected in ASGC tissues, while HER2 was weakly to moderately stained in normal anal sac apocrine glands and squamous epithelia. The degree of HER2 expression in ASGC tissues was scored based on its intensity and positivity (score: $0-3+$ ). Scoring of HER2 expression revealed 6 samples (24\%) scored $3+, 14(56 \%)$ scored $2+$, and $5(20 \%)$ scored $1+$, with no samples scoring 0 . In all, $80 \%$ of canine ASGC tissues were positive for HER2 (scored $\geq 2+$ ). Furthermore, putative HER2-overexpressed cells in ASGC were detected with trastuzumab by flow cytometry. These preliminary data may lead to further evaluation of the role of HER2 in canine ASGC as a mechanism of malignancy and as a therapeutic target for HER2-targeted therapy.

KEY WORDS: anal sac gland carcinoma, dog, oncogene protein human epidermal growth factor receptor 2

Canine anal sac gland carcinoma (ASGC) naturally develops in the apocrine glands of the anal sac of dogs, accounting for $2 \%$ of all canine skin tumors and up to $17 \%$ of all perianal tumors in dogs $[2,16]$. ASGC is an aggressive tumor described as both invasive and metastatic in nature, with reported metastatic rates of 47-96\% [3]. Many studies reported that metastatic disease develops during the early disease process and occurs most commonly in the regional lymph nodes [3, 18].

To date, multiple treatment options have been described against ASGC including surgery, radiotherapy, and chemotherapy [3]. Although one of the most effective therapy for local control is surgical resection, wide resection is sometimes difficult due to its local invasiveness [24]. Recently, conformal radiation therapy was reported to be more effective for stage 3b ASGC than surgery, but not all patients can undergo the therapy because availability of conformal radiation therapy is limited [12]. As a systemic therapy, some chemotherapeutics such as carboplatin, cisplatin, and actinomycin D have demonstrated anti-tumor activity in the gross disease setting; however, the role of adjuvant chemotherapy in the treatment of ASGC remains poorly defined [27]. Recently, several molecular-targeted drugs were developed for canine tumors. Toceranib phosphate (Palladia) is a receptor tyrosine kinase inhibitor and targets toceranib phosphate including several members of the split kinase family such as VEGFR, PDGFR, Kit, CSF-1, and Flt-3 [9, 28]. A study reported that the clinical benefits of toceranib phosphate were observed in 28 out of 32 dogs with

*Correspondence to: Kato, D.: feetkato@yahoo.co.jp

O2019 The Japanese Society of Veterinary Science

This is an open-access article distributed under the terms of the Creative Commons Attribution Non-Commercial No Derivatives (by-nc-nd) License. (CC-BY-NC-ND 4.0: https://creativecommons.org/licenses/by-nc-nd/4.0/) 
ASGC ( 8 with partial response and 20 with stable disease); however, side effects such as diarrhea, anorexia, and vomiting occurred in 66 out of 85 dogs [9]. Due to the aggressive nature of ASGC, more effective and less cytotoxic drugs to treat the tumors are required.

Human epidermal growth factor receptor 2 (HER2), a receptor tyrosine kinase, plays a crucial role in the development of normal tissue such as in the nervous system and mammary glands; however, it has also been known to regulate oncogenesis $[4,15]$. HER 2 has been reported to be strongly related to carcinogenesis of breast cancers via the activation of HER2-mediated signaling pathways caused by heterodimerization with ligand-activated HER1 or HER3 or by homodimerization when present in high concentrations [7]. Overexpression of HER2 has been reported in various human tumors such as breast, non-small cell lung, gastric, and ovarian cancers [10, 13, 20,23]. In canine tumors, overexpression of HER2 has only been reported in mammary gland tumors (MGTs), osteosarcomas (OSAs), and transitional cell carcinomas (TCCs) [5, 6, 14]. Overexpression of HER2 is also related to poor prognosis in various types of human tumors [12]. HER2 is thought to be one of the therapeutic targets in these tumors, and several drugs targeting HER2 have been developed [1]. Trastuzumab (Herceptin), a humanized antibody directed against the extracellular domain of human HER2, is used to prevent the metastasis of human breast cancer [25]. Lapatinib, a small molecule acting as a dual epidermal growth factor receptor (EGFR) and HER2 tyrosine kinase inhibitor, is approved for the treatment of human patients with HER2-positive breast cancers [1, 8]. These HER2-targeted drugs were clinically beneficial in human patients with HER2-positive tumors [1]. In contrast, information on HER2-targeted therapies is limited in veterinary medicine.

HER2-targeted drugs would be one of the promising drugs for dogs with ASGC. In this study, we aimed to investigate the expression of HER2 in canine ASGC.

\section{MATERIALS AND METHODS}

\section{Sample collection}

To evaluate the mRNA expression of HER2, fresh tumor and normal anal sac tissues were obtained from dogs with ASGC and healthy beagles, respectively. The tumor tissue was surgically removed from ASGC cases at the Veterinary Medical Center of the University of Tokyo between April 2017 and April 2018. To investigate the immunohistochemical expression of HER2, paraffinembedded tumor tissue of canine ASGC was analyzed. The tissue was surgically removed between January 2011 and December 2016. The tissue samples were diagnosed by veterinary pathologists certified by the Japanese College of Veterinary Pathologists at the Department of Veterinary Pathology at the University of Tokyo. All patients underwent the clinical staging, as previously described, by means of abdominal ultrasound examination, thoracic radiography, and computed tomography [18]. Fresh tumor tissue and metastatic lymph node tissue of ASGC were obtained from a dog to assess trastuzumab binding to canine HER2.

Permission for the collection and usage of resected tissue for this study was obtained from owners. Healthy dog tissue was obtained from healthy beagles euthanized for other experiments. All procedures were approved by the Animal Care and Use Committee at the University of Tokyo (Approval number: P17-074).

\section{Semi-quantification of $m R N A$ expression of HER2}

Total RNA was extracted and reverse transcribed using a transcriptase (ReverTra Ace, Toyobo, Osaka, Japan). Real-time polymerase chain reaction (PCR) was performed using a premix reagent (THUNDERBIRD SYBR qPCR Mix, Toyobo), specific primers for her2 (Forward primer: CAGCCCTGGTCACCTACAA, Reverse primer: CCACATCCGTAGACAGGTAG), and a realtime PCR system (StepOnePlus, Thermo Fisher Scientific, Waltham, MA, U.S.A.). mRNA expression was analyzed using standard curve method, and expression values were normalized using gapdh (Forward primer: TGACACCCACTCTTCCACCTTC, Reverse primer: CGGTTGCTGTAGCCAAATTCA) as an internal control.

\section{Immunohistochemical analysis}

Canine ASGC tissue was retrospectively evaluated. All samples were fixed in 10\% neutral-buffered formalin, embedded in paraffin wax, and cut into $4 \mu \mathrm{m}$-thick serial sections. Paraffin-embedded tumor sections were dewaxed and rehydrated in xylene and graded ethanol. Antigen retrieval was then performed using Dako Target Retrieval Solution, pH 9.0 (Agilent Technologies, Santa Clara, CA, U.S.A.) by microwaving for $15 \mathrm{~min}$ at $750 \mathrm{~W}$. After washing with tris-buffered saline containing $0.1 \%$ Tween 20 (TBS-t), endogenous peroxidase was blocked with 3\% hydrogen peroxide in methanol for 10 min. Specimens were then washed with TBS-t and incubated in $8 \%$ skimmed milk for $1 \mathrm{hr}$ at $20-28^{\circ} \mathrm{C}$ to reduce non-specific binding before overnight incubation with primary antibodies, which included mouse IgG1 anti-HER2 monoclonal antibodies (clone: CB-11, Leica biosystems, Wetzlar, Germany) diluted 1:40, at $4^{\circ} \mathrm{C}$ in a humidified chamber. A negative control was incubated with purified mouse IgG1, $\kappa$ isotype antibody (Clone: MG1-45, BioLegend, San Diego, CA, U.S.A.), under identical conditions. After washing with TBS-t, sections were incubated with a horseradish peroxidase (HRP)-conjugated anti-mouse antibody (Envision+ System-HRP Labelled Polymer; K4001; Agilent Technologies) for $30 \mathrm{~min}$ at $20-28^{\circ} \mathrm{C}$. Thereafter, the sections were washed with TBS-t, incubated with 3,3' diaminobenzidine (Dojindo Laboratories, Rockville, MD, U.S.A.) solution for 3 min, and counterstained with Mayer's hematoxylin. For the negative control, sections were subjected to the same procedures. The results were quantified according to the recent guidelines proposed by the American Society of Clinical Oncology/College of American Pathologists (ASCO/CAP) [17, 26].

\section{Flow cytometric analysis}

Fresh tumor and metastatic lymph node tissues were minced with scalpels and digested in $1 \mathrm{mg} / \mathrm{m} l$ collagenase I (Wako, Osaka, 
Japan) with $0.5 \%$ bovine serum albumin at $37^{\circ} \mathrm{C}$ for $2 \mathrm{hr}$. Undigested tissue was removed by filtration using a $100 \mu \mathrm{m}$ mesh. Cells were incubated with $200 \mu l$ of $10 \mu \mathrm{g} / \mathrm{ml}$ trastuzumab (Herceptin; Roche, Hertfordshire, U.K.) or without trastuzumab as negative control for $30 \mathrm{~min}$ at $4^{\circ} \mathrm{C}$, followed by three washes in fluorescence-activated cell sorting (FACS) buffer (phosphate-buffered saline containing 5\% fetal bovine serum). Then, cells were incubated with anti-human IgG APC antibodies (BioLegend) diluted 1:25 for $30 \mathrm{~min}$ at $4^{\circ} \mathrm{C}$, and washed with FACS buffer. Negative controls were also subjected to the same procedures. After live cells were gated by forward scatter/side scatter (FSC/SSC), fluorescence was measured and analyzed using a flow cytometer and its related software (BD FACSVerse ${ }^{\mathrm{TM}}$, Becton-Dickinson, Franklin Lakes, NJ, U.S.A.). Staining positivity was confirmed by negative control.

\section{Statistical analysis}

All data are shown as means \pm standard deviation (SD). The statistical methods and software used were Welch's $t$-test performed using the $\mathrm{R}$ software (R Development Core Team, 2018) and the beeswarm $\mathrm{R}$ package (Version 0.2.3, 2016). A $P<0.05$ was considered statistically significant.

\section{RESULTS}

\section{Evaluation of HER 2 mRNA in canine ASGC and normal anal sac tissue}

mRNA expression levels of HER2 were evaluated in ASGC $(n=6)$ and normal anal sac $(n=4)$ tissues. The average of HER2 mRNA expression in ASGC tissue was significantly higher than that in normal anal sac tissue (HER2/GAPDH: 0.67 vs 0.05 ; range: $0.26-1.68,0.02-0.24 ; P<0.05)$. Although various expression levels of HER2 were confirmed in ASGC tissue, it was elevated in all ASGC tissues compared to normal anal sac tissue (Fig. 1).

\section{Immunohistochemical expression of HER2 in canine ASGC}

A total of 25 ASGC tissue samples were collected from dogs ( 2 intact males, 13 castrated males, 5 intact females, and 5 spayed females) of different breeds (10 Miniature Dachshunds, 4 Chihuahuas, and 3 Toy Poodles). The mean age was $11.4 \pm 2.1$ (population SD), range: 6.8-15.2 years. Fifteen tumors were located on the left side and 10 on the right side; 5 cases (20\%) had stage 1 disease, and $9(36 \%), 8(32 \%), 2(8 \%)$, and 1 (4\%) had stage 2, 3a, 3b, and 4, respectively. Immunohistochemical staining revealed broad expression of HER2 in ASGC tissue. HER2-positive ASGC tissue demonstrated strong and broad staining of the circumferential membrane of ASGC cells (Fig. 2) and were negatively stained on the peri-tumor normal cells. On the other hand, HER2 was weakly to moderately expressed in a small part of normal anal sac tissue including apocrine glands and anal sac squamous epithelia (Fig. S2). To evaluate the staining pattern of HER2 in ASGC tissues, we scored the HER2 expression based

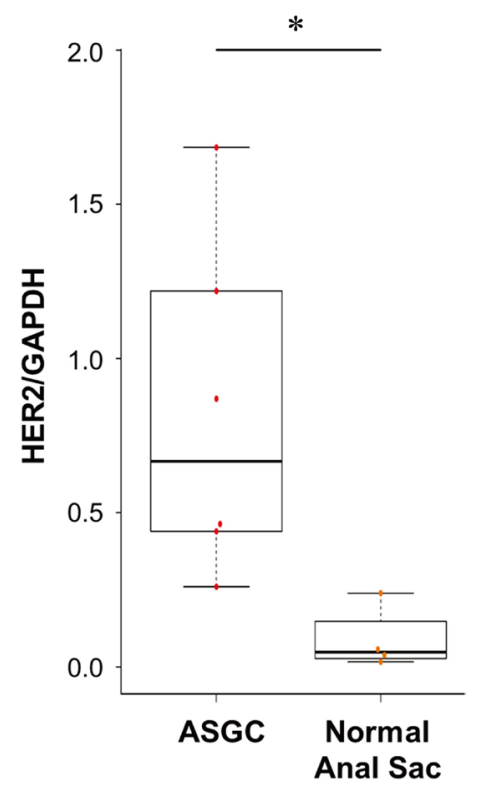

Fig. 1. Human epidermal growth factor receptor 2 (HER2) mRNA expression in anal sac gland carcinoma (ASGC) and normal anal sac tissues. HER2 mRNA expression in ASGC tissue was significantly higher than that in the normal anal sac tissues $(P<0.05)$.

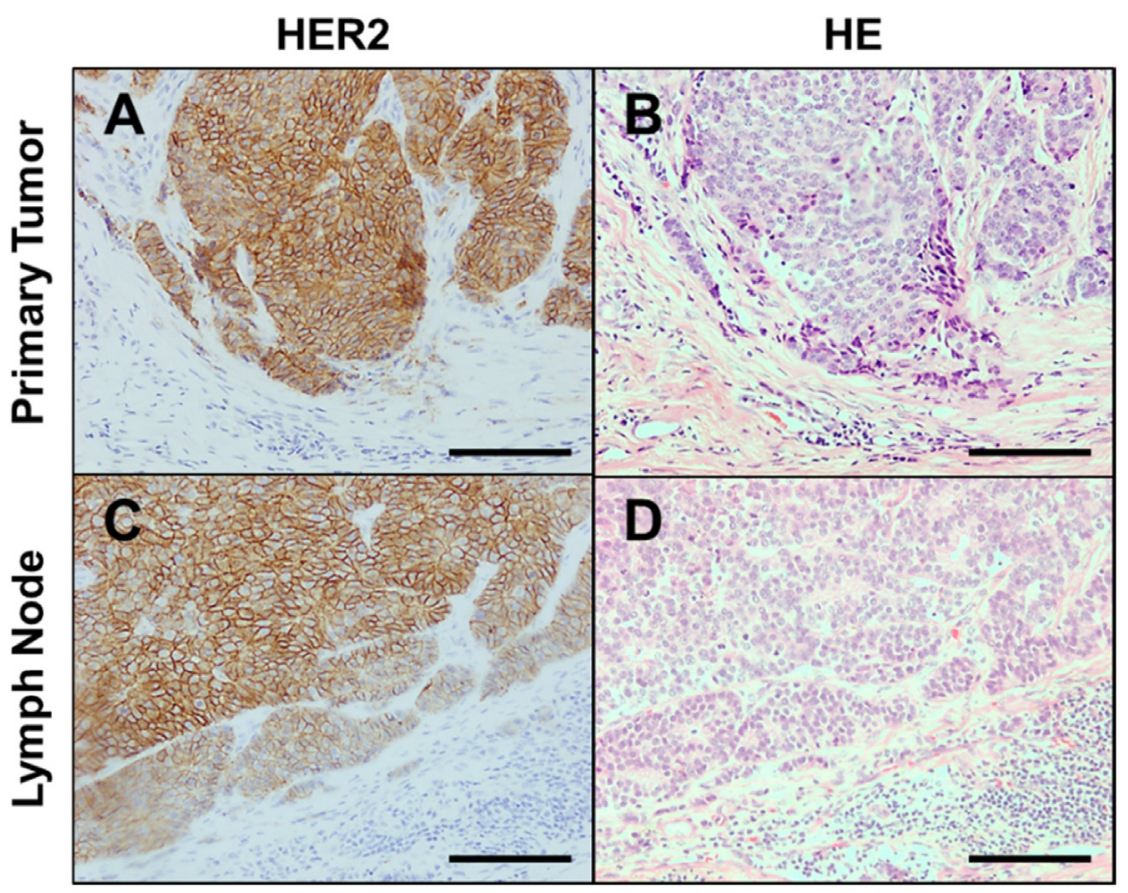

Fig. 2. Representative images of the staining pattern of Human epidermal growth factor receptor 2 (HER2) in canine anal sac gland carcinoma (ASGC). (A, C) Circumferential membrane staining that is complete and intense in canine ASGC cells in the primary tumor (A) and metastatic lymph node (C). (B, D) Hematoxylin and eosin staining of the primary tumor (B) and metastatic lymph node (D). Scale bar, $100 \mu \mathrm{m}$. 
Table 1. Human epidermal growth factor receptor 2 (HER2) scores in canine anal sac gland carcinoma (ASGC) tissue

\begin{tabular}{lcccc}
\hline & \multicolumn{2}{c}{ Negative } & \multicolumn{2}{c}{ Positive } \\
\hline Score & 0 & $1+$ & $2+$ & $3+$ \\
Number $(\%)$ & $0(0 \%)$ & $5(20 \%)$ & $14(56 \%)$ & $6(24 \%)$ \\
\hline
\end{tabular}

Table 2. Characteristics of the dogs and HER2 ${ }^{\text {a) }}$ expression

\begin{tabular}{|c|c|c|c|c|c|c|c|c|c|c|}
\hline \multirow{2}{*}{ No. } & \multirow{2}{*}{ Breed $^{b)}$} & \multirow{2}{*}{$\begin{array}{c}\text { Age } \\
\text { (years) }\end{array}$} & \multirow{2}{*}{$\operatorname{Sex}^{\mathrm{c})}$} & \multirow{2}{*}{ Location $^{\mathrm{d})}$} & \multicolumn{3}{|c|}{ TNM classification } & \multirow{2}{*}{$\begin{array}{l}\text { Clinical } \\
\text { stage }\end{array}$} & \multirow{2}{*}{$\begin{array}{c}\mathrm{IHC}^{\mathrm{e})} \text { score } \\
\text { (primary tumors) }\end{array}$} & \multirow{2}{*}{$\begin{array}{c}\text { IHC scoref) } \\
\text { (lymph nodes) }\end{array}$} \\
\hline & & & & & $\mathrm{T}$ & $\mathrm{N}$ & $\mathrm{M}$ & & & \\
\hline 1 & MD & 9.3 & $\mathrm{MC}$ & $\mathrm{R}$ & $\mathrm{T} 1$ & N0 & M0 & 1 & $2+$ & - \\
\hline 2 & JRT & 13.7 & MC & $\mathrm{R}$ & $\mathrm{T} 2$ & N0 & M0 & 1 & $2+$ & - \\
\hline 3 & MD & 9.8 & $\mathrm{MC}$ & $\mathrm{L}$ & $\mathrm{T} 2$ & N0 & M0 & 1 & $2+$ & - \\
\hline 4 & MD & 12.2 & $\mathrm{MC}$ & $\mathrm{R}$ & $\mathrm{T} 2$ & No & M0 & 1 & $2+$ & - \\
\hline 5 & MD & 12.4 & M & $\mathrm{L}$ & $\mathrm{T} 2$ & N0 & M0 & 2 & $1+$ & - \\
\hline 6 & MD & 13.3 & MC & $\mathrm{L}$ & $\mathrm{T} 2$ & N0 & M0 & 2 & $1+$ & - \\
\hline 7 & GR & 11.5 & $\mathrm{MC}$ & $\mathrm{L}$ & $\mathrm{T} 2$ & N0 & M0 & 2 & $1+$ & - \\
\hline 8 & $\mathrm{TP}$ & 11.7 & $\mathrm{~F}$ & $\mathrm{~L}$ & $\mathrm{~T} 2$ & N0 & M0 & 2 & $2+$ & - \\
\hline 9 & FB & 9.4 & $\mathrm{MC}$ & $\mathrm{L}$ & $\mathrm{T} 2$ & N0 & M0 & 2 & $2+$ & - \\
\hline 10 & MD & 9.0 & $\mathrm{MC}$ & $\mathrm{L}$ & $\mathrm{T} 2$ & N0 & M0 & 2 & $2+$ & - \\
\hline 11 & MD & 10.4 & $\mathrm{M}$ & $\mathrm{R}$ & $\mathrm{T} 2$ & N0 & M0 & 2 & $2+$ & - \\
\hline 12 & GR & 9.9 & $\mathrm{MC}$ & $\mathrm{R}$ & T3 & N0 & M0 & 2 & $2+$ & - \\
\hline 13 & $\mathrm{CH}$ & 12.0 & $\mathrm{MC}$ & $\mathrm{L}$ & $\mathrm{T} 2$ & N0 & M0 & 2 & $3+$ & - \\
\hline 14 & MD & 12.4 & FS & $\mathrm{L}$ & $\mathrm{T} 2$ & $\mathrm{~N} 1 \mathrm{~b}$ & M0 & $3 a$ & $1+$ & N/A \\
\hline 15 & $\mathrm{TP}$ & 9.6 & $\mathrm{~F}$ & $\mathrm{R}$ & $\mathrm{T} 1$ & $\mathrm{~N} 2 \mathrm{~b}$ & M0 & $3 a$ & $2+$ & 3 \\
\hline 16 & TP & 6.8 & F & $\mathrm{L}$ & $\mathrm{T} 2$ & $\mathrm{~N} 1 \mathrm{~b}$ & M0 & $3 a$ & $2+$ & N/A \\
\hline 17 & SS & 11.3 & FS & $\mathrm{L}$ & $\mathrm{T} 2$ & $\mathrm{~N} 1 \mathrm{~b}$ & M0 & $3 a$ & $2+$ & N/A \\
\hline 18 & MD & 11.1 & $\mathrm{MC}$ & $\mathrm{L}$ & $\mathrm{T} 1$ & $\mathrm{~N} 1 \mathrm{~b}$ & M0 & $3 a$ & $3+$ & N/A \\
\hline 19 & $\mathrm{CH}$ & 14.6 & $\mathrm{MC}$ & L & $\mathrm{T} 1$ & $\mathrm{~N} 1 \mathrm{~b}$ & M0 & $3 a$ & $3+$ & N/A \\
\hline 20 & BG & 14.3 & $\mathrm{~F}$ & $\mathrm{~L}$ & $\mathrm{~T} 2$ & $\mathrm{~N} 1 \mathrm{~b}$ & M0 & $3 a$ & $3+$ & N/A \\
\hline 21 & $\mathrm{CH}$ & 15.2 & $\mathrm{MC}$ & $\mathrm{L}$ & $\mathrm{T} 2$ & N1b & M0 & $3 a$ & $3+$ & N/A \\
\hline 22 & SI & 11.3 & FS & $\mathrm{R}$ & $\mathrm{T} 2$ & $\mathrm{~N} 1 \mathrm{~b}$ & M0 & $3 b$ & $2+$ & 2 \\
\hline 23 & $\mathrm{SH}$ & 11.8 & $\mathrm{~F}$ & $\mathrm{R}$ & $\mathrm{T} 2$ & $\mathrm{~N} 1 \mathrm{~b}$ & M0 & $3 b$ & $3+$ & 3 \\
\hline 24 & MD & 13.4 & FS & $\mathrm{R}$ & $\mathrm{T} 1$ & $\mathrm{~N} 2 \mathrm{~b}$ & M1 & 4 & $1+$ & N/A \\
\hline 25 & $\mathrm{CH}$ & 8.3 & FS & $\mathrm{R}$ & $\mathrm{T} 1$ & N0 & M1 & 4 & $2+$ & - \\
\hline
\end{tabular}

a) HER2: Human epidermal growth factor receptor 2. b) MD: Miniature Dachshund, JRT: Jack Russell Terrier, GR: Golden Retriever, TP: Toy Poodle, FB: French Bulldog, CH: Chihuahua, SS: Shetland Sheepdog, BG: Beagle, SI: Shiba Inu, SH: Siberian Husky. c) MC: Male castrated, M: Male, FS: Female spayed, F: Female. d) R: Right, L: Left. e) IHC: Immunohistochemistry. f) -: No lymph node metastasis, N/A: Not available due to non-resectable tumor.

on the ASCO/CAP guidelines (Table S1). Representative images of the staining pattern for each score are shown in Fig. S1.

Analysis of HER2 expression score demonstrated that 6 samples (24\%) scored 3+, $14(56 \%)$ scored 2+, and $5(20 \%)$ scored 1+, with no samples scoring 0 (Table 1). In total, $80 \%$ of canine ASGC tissue was positive for HER2 (scored $>2+$ ). No correlation was observed between HER2 score and clinical data. HER2 expression score and clinical diagnosis of each patient are shown in Table 2.

\section{Flow cytometric assessment of trastuzumab binding to HER2 in canine ASGC}

To evaluate the surface expression of HER2 and recognition of canine HER2 overexpressed on ASGC cells by trastuzumab, fresh primary ASGC and metastatic lymph node tissues were obtained from a dog (9 years old, Miniature Schnauzer, T1N2bM0, stage3a) to assess trastuzumab binding to canine HER2. Most of the cells in the primary and metastatic tumor tissues were clearly stained by trastuzumab (Fig. 3).

\section{DISCUSSION}

Overexpression of HER2 has been reported in various human tumors and HER2 was reported to be associated with clinical prognosis such as survival time and overall survival. In dogs, HER2 was reported to be expressed in $20 \%$ of MGT patients, $40 \%$ of OSA patients, and $56 \%$ of TCC patients $[5,6,14]$. In this study, broad overexpression of HER2 was detected in $80 \%$ of canine ASGC patients, indicating that HER2 might potentially be a cause of malignancy in tumors and a therapeutic target in canine ASGC. As the correlation between HER2 overexpression and tumor development was reported in human patients with HER2- 


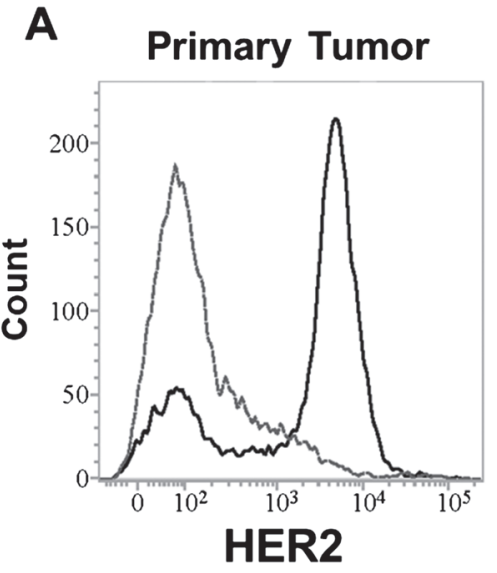

\section{B Metastatic Tumor}

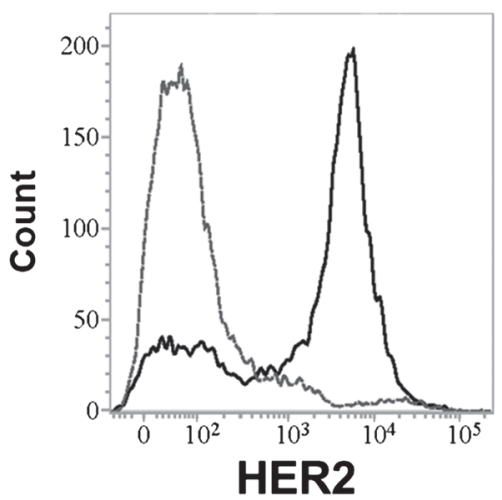

Fig. 3. Human epidermal growth factor receptor 2 (HER2) expression in the primary tumor (A) and metastatic lymph node (B) by flow cytometric analysis (gray dotted line: negative control, black solid line: trastuzumab). The tumor cells from both the primary tumor and metastatic lymph node were positive for HER2, and trastuzumab could bind to canine anal sac gland carcinoma cells.

positive tumors [15], we evaluated the association of HER2 expression with clinical data in our samples. No correlation between HER2 expression and clinical characteristics such as breed, sex, clinical stage, and prognosis was observed in this study. As this study evaluated a limited number of patients with canine ASGC, further studies are required to investigate the association between HER2 expression and the malignancy of ASGC.

In human medicine, multiple drugs targeting HER2-positive tumors have been developed in the last two decades [1]. Trastuzumab (Herceptin) is a recombinant humanized IgG monoclonal antibody that targets the extracellular domain of HER2 [25]. A large clinical trial has demonstrated the improvement of clinical outcome with the addition of trastuzumab compared to chemotherapy alone, and the study reported that the administration of trastuzumab improved the disease-free survival rate at 5 years by $13 \%$ in human patients with breast cancer [22]. Singer et al. reported a $92 \%$ amino acid homology between canine and human erbB-2 (which encodes HER2) and confirmed the binding of trastuzumab to canine HER2 expressed on MGTs cells [21]. In our study, flow cytometric analysis showed that trastuzumab also bound to canine HER2 expressed on ASGC cells, and overexpressed HER2 was localized on the membrane. These findings indicated that trastuzumab might be useful as a therapeutic tool for canine patients with ASGC expressing HER2, such as for tumor antigen targeting therapies (e.g. cytotoxic antibody therapy of canine chimeric antibodies and chimeric antigen receptor T-cell therapy).

Lapatinib is a small molecule targeting the intracellular tyrosine kinase domain of HER2. Clinical trials of the combination therapy of lapatinib and the chemotherapeutic drug, capecitabine, in human patients with advanced breast cancers demonstrated a significant improvement of progression-free survival compared to chemotherapy alone (8.4 vs. 4.4 months) [8]. Lapatinib was reported to cross-react with the canine tyrosine kinase domain of HER2 [19] and is of relatively low cost compared to cytotoxic antibodies. Therefore, lapatinib is easily used in a clinical setting for dogs with ASGC. Although the main mechanisms of the anti-tumor effects of lapatinib were reported to be due to the inhibition of abnormal HER2 signaling, further studies are required to investigate the effects on the downstream signaling pathways of HER2, such as the PI3K/AKT and RAS/MAPK pathways, in ASGC [8]. Moreover, immune therapy targeting HER2 has been investigated in patients with canine tumor. Recombinant Listeria vaccines expressing a chimeric human HER2/neu fusion protein (ADXS31-164) were evaluated in canine OSA in a phase I trial [11], which demonstrated that the HER2 vaccine prevents pulmonary metastasis and prolongs survival in dogs with HER2-positive appendicular OSA. The HER2 vaccine might potentially be an effective systemic therapy in canine ASGC.

Our study demonstrated that HER2 mRNA expression in ASGC tissue was higher than that in normal anal sac tissues, and 80\% of canine ASGC tissues strongly expressed HER2 on the circumferential membrane of tumor cells. Our preliminary data would lead to further evaluation of the role of HER2 in canine ASGC as a marker of malignancy and a therapeutic target in patients with canine ASGC.

CONFLICTS OF INTEREST. The authors declare to have no conflicts of interest.

\section{REFERENCES}

1. Awada, G., Gombos, A., Aftimos, P. and Awada, A. 2016. Emerging drugs targeting human epidermal growth factor receptor 2 (HER2) in the treatment of breast cancer. Expert Opin. Emerg. Drugs 21: 91-101. [Medline] [CrossRef]

2. Bennett, P. F., DeNicola, D. B., Bonney, P., Glickman, N. W. and Knapp, D. W. 2002. Canine anal sac adenocarcinomas: clinical presentation and response to therapy. J. Vet. Intern. Med. 16: 100-104. [Medline] [CrossRef]

3. Brown, R. J., Newman, S. J., Durtschi, D. C. and Leblanc, A. K. 2012. Expression of PDGFR- $\beta$ and Kit in canine anal sac apocrine gland 
adenocarcinoma using tissue immunohistochemistry. Vet. Comp. Oncol. 10: 74-79. [Medline] [CrossRef]

4. Casalini, P., Iorio, M. V., Galmozzi, E. and Ménard, S. 2004. Role of HER receptors family in development and differentiation. J. Cell. Physiol. 200: 343-350. [Medline] [CrossRef]

5. Flint, A. F., U'Ren, L., Legare, M. E., Withrow, S. J., Dernell, W. and Hanneman, W. H. 2004. Overexpression of the erbB-2 proto-oncogene in canine osteosarcoma cell lines and tumors. Vet. Pathol. 41: 291-296. [Medline] [CrossRef]

6. Gama, A., Alves, A. and Schmitt, F. 2008. Identification of molecular phenotypes in canine mammary carcinomas with clinical implications: application of the human classification. Virchows Arch. 453: 123-132. [Medline] [CrossRef]

7. Hsu, J. L. and Hung, M. C. 2016. The role of HER2, EGFR, and other receptor tyrosine kinases in breast cancer. Cancer Metastasis Rev. 35: 575-588. [Medline] [CrossRef]

8. Hurvitz, S. A. and Kakkar, R. 2012. Role of lapatinib alone or in combination in the treatment of HER2-positive breast cancer. Breast Cancer (Dove Med. Press) 4: 35-51. [Medline]

9. London, C., Mathie, T., Stingle, N., Clifford, C., Haney, S., Klein, M. K., Beaver, L., Vickery, K., Vail, D. M., Hershey, B., Ettinger, S., Vaughan, A., Alvarez, F., Hillman, L., Kiselow, M., Thamm, D., Higginbotham, M. L., Gauthier, M., Krick, E., Phillips, B., Ladue, T., Jones, P., Bryan, J., Gill, V., Novasad, A., Fulton, L., Carreras, J., McNeill, C., Henry, C. and Gillings, S. 2012. Preliminary evidence for biologic activity of toceranib phosphate (Palladia( $(\mathbb{B}))$ in solid tumours. Vet. Comp. Oncol. 10: 194-205. [Medline] [CrossRef]

10. Luo, H., Xu, X., Ye, M., Sheng, B. and Zhu, X. 2018. The prognostic value of HER2 in ovarian cancer: A meta-analysis of observational studies. PLoS One 13: e191972. [Medline] [CrossRef]

11. Mason, N. J., Gnanandarajah, J. S., Engiles, J. B., Gray, F., Laughlin, D., Gaurnier-Hausser, A., Wallecha, A., Huebner, M. and Paterson, Y. 2016. Immunotherapy with a HER2-targeting listeria induces HER2-specific immunity and demonstrates potential therapeutic effects in a phase I trial in canine osteosarcoma. Clin. Cancer Res. 22: 4380-4390. [Medline] [CrossRef]

12. Meier, V., Polton, G., Cancedda, S., Roos, M., Laganga, P., Emmerson, T. and Rohrer Bley, C. 2017. Outcome in dogs with advanced (stage 3b) anal sac gland carcinoma treated with surgery or hypofractionated radiation therapy. Vet. Comp. Oncol. 15: 1073-1086. [Medline] [CrossRef]

13. Ménard, S., Fortis, S., Castiglioni, F., Agresti, R. and Balsari, A. 2001. HER2 as a prognostic factor in breast cancer. Oncology 61 Suppl 2: 67-72. [Medline] [CrossRef]

14. Millanta, F., Impellizeri, J., McSherry, L., Rocchigiani, G., Aurisicchio, L. and Lubas, G. 2018. Overexpression of HER-2 via immunohistochemistry in canine urinary bladder transitional cell carcinoma - A marker of malignancy and possible therapeutic target. Vet. Comp. Oncol. 16: 297-300. [Medline] [CrossRef]

15. Moasser, M. M. 2007. The oncogene HER2: its signaling and transforming functions and its role in human cancer pathogenesis. Oncogene 26: 6469-6487. [Medline] [CrossRef]

16. Palladino, S., Keyerleber, M. A., King, R. G. and Burgess, K. E. 2016. Utility of computed tomography versus abdominal ultrasound examination to identify iliosacral lymphadenomegaly in dogs with apocrine gland adenocarcinoma of the anal sac. J. Vet. Intern. Med. 30: 1858-1863. [Medline] [CrossRef]

17. Perez, E. A., Cortés, J., Gonzalez-Angulo, A. M. and Bartlett, J. M. S. 2014. HER2 testing: current status and future directions. Cancer Treat. Rev. 40: 276-284. [Medline] [CrossRef]

18. Polton, G. A. and Brearley, M. J. 2007. Clinical stage, therapy, and prognosis in canine anal sac gland carcinoma. J. Vet. Intern. Med. 21: 274-280. [Medline] [CrossRef]

19. Sakai, K., Maeda, S., Saeki, K., Nakagawa, T., Murakami, M., Endo, Y., Yonezawa, T., Kadosawa, T., Mori, T., Nishimura, R. and Matsuki, N. 2018. Anti-tumour effect of lapatinib in canine transitional cell carcinoma cell lines. Vet. Comp. Oncol. 16: 642-649. [Medline] [CrossRef]

20. Shao, X., Kuai, X., Pang, Z., Zhang, L., Wu, L., Xu, L. and Zhou, C. 2018. Correlation of Gli1 and HER2 expression in gastric cancer: Identification of novel target. Sci. Rep. 8: 397. [Medline] [CrossRef]

21. Singer, J., Weichselbaumer, M., Stockner, T., Mechtcheriakova, D., Sobanov, Y., Bajna, E., Wrba, F., Horvat, R., Thalhammer, J. G., Willmann, M. and Jensen-Jarolim, E. 2012. Comparative oncology: ErbB-1 and ErbB-2 homologues in canine cancer are susceptible to cetuximab and trastuzumab targeting. Mol. Immunol. 50: 200-209. [Medline] [CrossRef]

22. Slamon, D., Eiermann, W., Robert, N., Pienkowski, T., Martin, M., Press, M., Mackey, J., Glaspy, J., Chan, A., Pawlicki, M., Pinter, T., Valero, V., Liu, M. C., Sauter, G., von Minckwitz, G., Visco, F., Bee, V., Buyse, M., Bendahmane, B., Tabah-Fisch, I., Lindsay, M. A., Riva, A., Crown J., Breast Cancer International Research Group. 2011. Adjuvant trastuzumab in HER2-positive breast cancer. N. Engl. J. Med. 365: 1273-1283. [Medline] [CrossRef]

23. Suzuki, M., Shiraishi, K., Yoshida, A., Shimada, Y., Suzuki, K., Asamura, H., Furuta, K., Kohno, T. and Tsuta, K. 2015. HER2 gene mutations in non-small cell lung carcinomas: concurrence with Her2 gene amplification and Her2 protein expression and phosphorylation. Lung Cancer 87: 14-22. [Medline] [CrossRef]

24. Turek, M. M. and Withrow, S. J. 2012. Perianal tumors. pp. 423-431. In: Small Animal Clinical Oncology, 5th ed. (Withrow, S. J., Vail, D. M. and Page, R. L. eds.), Elsevier, Amsterdam.

25. Vogel, C. L. and Franco, S. X. 2003. Clinical experience with trastuzumab (herceptin). Breast J. 9: 452-462. [Medline] [CrossRef]

26. Wolff, A. C., Hammond, M. E. H., Hicks, D. G., Dowsett, M., McShane, L. M., Allison, K. H., Allred, D. C., Bartlett, J. M. S., Bilous, M., Fitzgibbons, P., Hanna, W., Jenkins, R. B., Mangu, P. B., Paik, S., Perez, E. A., Press, M. F., Spears, P. A., Vance, G. H., Viale, G., Hayes D. F., American Society of Clinical Oncology College of American Pathologists. 2013. Recommendations for human epidermal growth factor receptor 2 testing in breast cancer: American Society of Clinical Oncology/College of American Pathologists clinical practice guideline update. J. Clin. Oncol. 31: 3997-4013. [Medline] [CrossRef]

27. Wouda, R. M., Borrego, J., Keuler, N. S. and Stein, T. 2016. Evaluation of adjuvant carboplatin chemotherapy in the management of surgically excised anal sac apocrine gland adenocarcinoma in dogs. Vet. Comp. Oncol. 14: 67-80. [Medline] [CrossRef]

28. Wouda, R. M., Hocker, S. E. and Higginbotham, M. L. 2018. Safety evaluation of combination carboplatin and toceranib phosphate (Palladia) in tumour-bearing dogs: A phase I dose finding study. Vet. Comp. Oncol. 16: E52-E60. [Medline] [CrossRef] 